\title{
Electroanalysis of Neutral Precursors in Protic Ionic Liquids and Synthesis of High-Ionicity Ionic Liquids
}

Sean E. Goodwin, ${ }^{1}$ Daniel E. Smith, ${ }^{1}$ Joshua S. Gibson, ${ }^{2}$ Robert G. Jones, ${ }^{2}$ and Darren A. Walsh ${ }^{1}$

${ }^{1}$ School of Chemistry and GSK Carbon Neutral Laboratory for Sustainable Chemistry The University of Nottingham, Jubilee Campus

Nottingham NG7 2TU, UK

${ }^{2}$ Department of Physical Chemistry

School of Chemistry

The University of Nottingham, University Park

Nottingham NG7 2RD, UK

*darren.walsh@nottingham.ac.uk; Tel: +44 115 8467495; Fax: +44 1159513562 


\begin{abstract}
Protic ionic liquids (PILs) are ionic liquids that are formed by transferring protons from Brønsted acids to Brønsted bases. While they nominally consist entirely of ions, PILs can often behave as though they contain a significant amount of neutral species (either molecules or ion clusters), and there is currently a lot of interest in determining the degree of "ionicity" of PILs. In this contribution, we describe a simple electroanalytical method for detecting and quantifying residual excess acids in a series of ammonium-based PILs (diethylmethylammonium triflate, [dema][TfO], dimethylethylammonium triflate, [dmea][TfO], triethylammonium trifluoroacetate, $[$ tea][TfAc], and dimethylbutylammonium triflate $[\mathrm{dmba}][\mathrm{TfO}])$ Ultramicroelectrode voltammetry reveals that some of the accepted methods for synthesising PILs can readily result in the formation of non-stoichiometric PILs containing up to $230 \mathrm{mM}$ excess acid. In addition, vacuum purification of PILs is of limited use in cases where non-stoichiometric PILs are formed. While excess bases can be readily removed from PILs, even under ambient conditions, excess acids cannot, even under high vacuum. The effects of excess acid on the electrocatalytic oxygen reduction reaction (ORR) in PILs have been studied, and the onset potential of the ORR in [dema][TfO] increases by $0.8 \mathrm{~V}$ upon addition of excess acid to PIL. Based on the results of our analyses, we provide some recommendations for the synthesis of highly-ionic PILs.
\end{abstract}




\section{Introduction}

Room temperature ionic liquids (RTILs) are defined as species consisting entirely of ions and which are liquid below $100{ }^{\circ} \mathrm{C} .{ }^{1}$ Due to their low vapor pressures, wide electrochemical windows, and inherent conductivities, RTILs are being used in a wide range of applications, such as catalysis, ${ }^{2}$ synthesis, ${ }^{3}$ electrodeposition, ${ }^{4}$ sensing, ${ }^{5}$ and energy conversion and storage. ${ }^{6-7}$ In each case, the physicochemical properties of the RTILs are the main drivers for their selection, and understanding the structure-property relationships of these media is an extremely active area of research. A major theme in this research is understanding the degree of "ionicity" of RTILs (or how much of the RTILs actually comprises free ions). It is clear that some RTILs behave as though they are not composed entirely of free ions, exhibiting relatively high vapor pressures and low ionic conductivities. ${ }^{8-15}$ Such phenomena are often particularly evident in protic ionic liquids (PILs), which are RTILs formed by transferring protons from Brønsted acids to Brønsted bases. Depending on the degree of proton transfer during synthesis, PILs can actually comprise a mixture of the salt, the parent acid, and the parent base, reducing the ionicity of the liquids. It has also been proposed that the formation of long-lived ion pairs and ion clusters within the liquids can lower the degree of ionicity.

At present, there are no simple methods for unambiguously determining the degree of ionicity of PILs. However, qualitative estimates based on measurements of ionic conductivity are extremely common, and often involve use of the Walden rule:

$$
\Lambda \eta=k
$$


where $\Lambda$ is the molar conductivity, $\eta$ is the viscosity, and $k$ is a temperature-dependent constant. The data for fully-dissociated, strong electrolytes such as dilute aqueous $\mathrm{KCl}$ lie along the ideal Walden line of $\log \Lambda v s . \log \eta^{-1}$, where $\eta^{-1}$ is the "fluidity" of the medium, but the conductivities of PILs tend to fall significantly below the ideal line, providing a qualitative estimate of ionicity. ${ }^{16}$ However, conductivity measurements cannot distinguish between the presence of neutral ion pairs, neutral ion clusters, and neutral molecules in the liquids. Due to such difficulties, Macfarlane has suggested that the ionicity of PILs be simply defined as the "effective fraction of ions available to participate in conduction." ${ }^{, 17}$

A number of alternatives to conductimetry have been proposed for studying the ionicity of PIL, including the analysis of PIL vapors and NMR spectroscopy. Analysis of PIL vapors demonstrates that back proton transfer from the protonated base to the deprotonated acid can occur at elevated temperatures ${ }^{18-19}$ but cannot provide insights into the concentration of precursors in an "as-synthesised" liquid. ${ }^{1} \mathrm{H}$ NMR spectroscopy can reveal the degree of shielding of the PIL cations' exchangeable protons but measuring the extent of protonation of the basic site is complicated by the presence of protic impurities such as $\mathrm{H}_{2} \mathrm{O}$, and fast exchange of protons between the components of the PILs. ${ }^{20-21}{ }^{15} \mathrm{~N}$ NMR spectroscopy is another option for studying the extent of protonation of amine basic sites, but is complicated by interference from hydrogen bonding. ${ }^{16,22}$ As such, qualitative methods such as use of Walden plots remain popular in studies of the ionicity of PILs. The usefulness and popularity of such qualitative methods are in part due to the frequent correlation between the conductivity of PILs and differences in the aqueous $\mathrm{p} K_{\mathrm{a}} \mathrm{s}$ of the parent acids and bases $\left(\Delta \mathrm{p} K_{\mathrm{a}}\right)$ used to make PILs. $\Delta \mathrm{p} K_{\mathrm{a}}$ represents the driving force for proton transfer and, while $\Delta \mathrm{p} K_{\mathrm{a}}>3$ is sufficient for near-complete proton transfer in aqueous solutions, it is generally believed that $\Delta \mathrm{p} K_{\mathrm{a}}$ values greater than about 10 lead to highly-ionic (or good) PILs. ${ }^{14-15,23}$ However, Macfarlane and co-workers have demonstrated 
the weakness of the use of aqueous $\mathrm{p} K_{\mathrm{a}} \mathrm{s}$ as a guide for designing PILs. ${ }^{22}$ They found that the required $\Delta \mathrm{p} K_{\mathrm{a}}$ for effectively complete proton transfer actually depends on the nature of the amine used to form ammonium-based PILs. A series of primary amines deprotonated an indicator acid at $\Delta \mathrm{p} K_{\mathrm{a}}=3$ but $\Delta \mathrm{p} K_{\mathrm{a}}=10$ was required to deprotonate tertiary amines, a factor that was attributed to the different H-bonding abilities of the species, due to steric hindrance of hydrogen bonding to tertiary amines.

Complicating studies of ionicity of PILs, and the identification of methods for synthesising highly-ionic PILs, is the range of methods that are used for their synthesis. PILs have been synthesised using stoichiometric addition of neat acid to neat base, either with or without an excess of base, ${ }^{15-16,20-22,24-31}$ and addition of acid to base with at least one component in solution. ${ }^{15,31-33}$ To mitigate the risk of losing volatile components from reaction mixtures, the importance of keeping reaction mixtures cold using water-ice baths or dry ice-acetone baths is often stressed. $^{15,34}$ It has been claimed that non-stoichiometric PILs can be purified by evaporating excess neutral molecules under vacuum, ${ }^{28}$ but others have warned against purifying PILs by vacuum drying, in case it exacerbates non-stoichiometry. ${ }^{11,16,35}$ Compounding the problem is the absence of a reliable method for detect and quantify the concentration of unreacted precursor species in PILs, making it difficult to compare different methods for synthesising PILs.

In this paper, we describe a simple voltammetric method that can be used to rapidly assess the quality of a series of ammonium-based PILs, a class of PILs that is often used in electrochemical studies and devices. ${ }^{6,36-37}$ We show significant differences in the ultramicroelectrode (UME) voltammetry of the PILs diethylmethylammonium triflate $[\mathrm{dema}][\mathrm{TfO}]$, dimethylethylammonium triflate $[\mathrm{dmea}][\mathrm{TfO}]$, triethylammonium trifluoroacetate [tea][TfAc], and dimethylbutylammonium triflate $[\mathrm{dmba}][\mathrm{TfO}]$ when prepared using different 
<smiles>CC[N+](C)(C)CC</smiles>

[dema][TfO]

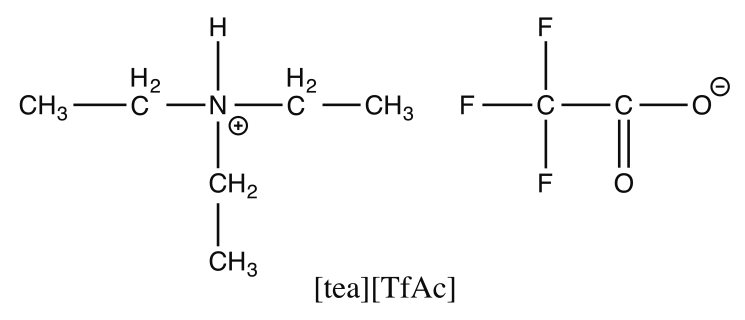

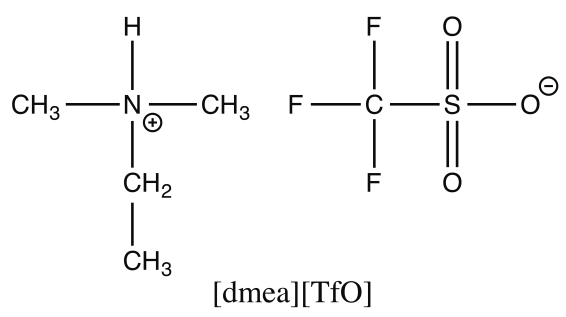

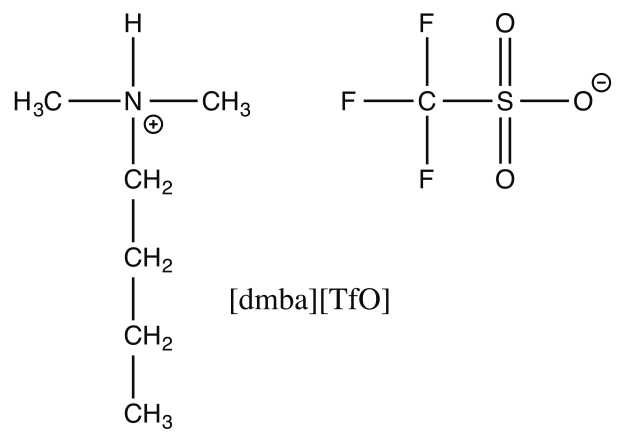

Scheme 1. Structures of the protic ionic liquids [dema][TfO], [dmea][TfO], [tea][TfAc], and [dmba][TfO].

literature methods. We demonstrate that this difference is caused by the presence of a significant concentration of excess parent acids in some PILs, particularly those formed by addition of neat parent acids to neat bases. Using our method, we quantify the excess acids present in some PILs and show that the acid can be extremely stable in PILs. For example, excess triflic acid, TfOH, persists in [dema][TfO] even when the PIL is held under high vacuum $\left(\sim 10^{-7} \mathrm{mbar}\right)$ for several weeks. In contrast, quantification of excess bases in PILs is complicated by evaporation of the bases from the PILs within hours, even at atmospheric pressure. We also demonstrate the limitations of ${ }^{1} \mathrm{H}$ NMR spectroscopy and conductimetry for measuring the concentration of excess acids in these media and, based on our observations, we make a number of recommendations for the synthesis of PILs with high ionicity. Finally, we show that the excess acids can have a significant effect on the chemical and electrochemical properties of the liquids. 


\section{Experimental}

Materials and Apparatus. All reagents were from Alfa Aesar or Sigma Aldrich and were used as received. $\mathrm{H}_{2}(99.995 \%)$, $\mathrm{Ar}(99.998 \%), \mathrm{O}_{2}(99.998 \%)$, and $\mathrm{N}_{2}(99.998 \%)$ were from BOC gases (Nottingham, UK). Au wire (0.5-mm diameter, 99.9985\%), Pt wire (0.5-mm diameter, 99.997\%, and 0.025 $\mathrm{mm}$ diameter, 99.95\%), and $\mathrm{Pd}$ wire (0.1 $\mathrm{mm}$ diameter, 99.99\%) were from Alfa Aesar. Electrochemical measurements were carried out using model 910B and CH1140 potentiostats (CH Instruments, Austin, TX)

Synthesis and Characterization of Ionic Liquids. PILs were synthesised by adding the appropriate parent acids to bases, while the bases were kept cold in ice baths. Three methods were used to synthesise PILs: (A) neat acids were slowly added to a 5\% molar excess of neat base, (B) neat acids were added to a 15\% molar excess of neat base, and (C) $1.0 \mathrm{M}$ aqueous acids were added to a $5 \%$ molar excess of neat base, and excess $\mathrm{H}_{2} \mathrm{O}$ was then removed using rotary evaporation. After synthesis, all PILs were heated to $70{ }^{\circ} \mathrm{C}$ under vacuum $\left(3 \times 10^{-2}\right.$ mbar $)$ for 48 hr to remove excess water and base. PILs were characterised by ${ }^{1} \mathrm{H}$ NMR spectroscopy, and residual water contents were determined using Karl Fischer titrations (Mitsubishi CA100). In all instances, residual water contents were below 200 ppm.

Electrode Fabrication and Electrochemical Measurements. The use of $\mathrm{Pd} / \mathrm{H}$ reference electrodes for electrochemistry in PILs was introduced by Angell. ${ }^{31} \mathrm{Pd} / \mathrm{H}$ electrodes provide stable potentials in PILs, which are defined by the hydrogen-redox equilibrium at the interface between the $\mathrm{Pd}$ and the PIL. $\mathrm{Pd} / \mathrm{H}$ reference electrodes were fabricated by sealing $\mathrm{Pd}$ wires $(\sim 2$ $\mathrm{cm}$ ) into borosilicate glass using a butane flame. $\sim 1 \mathrm{~cm}$ of the $\mathrm{Pd}$ wires was left protruding from the glass sheaths to form $\mathrm{Pd}$ rod electrodes. $\mathrm{Cu}$ contact wires were attached to the $\mathrm{Pd}$ wires inside the glass sheath using Ag epoxy (Chemtronics, Kennesaw, GA). The Pd rods were then annealed in a butane flame, then immersed in water, and $\mathrm{H}_{2}$ was bubbled over the metal surfaces 
for $30 \mathrm{~min}$. The rods were then rinsed with water and then dried under a flow of $\mathrm{N}_{2} .25-\mu \mathrm{m} \mathrm{Pt}$ disk UMEs were prepared by sealing $25-\mu \mathrm{m}$ diameter Pt wires in soft glass, and then grinding and polishing the end of the UMEs until smooth Pt disks were exposed (using the methods described in Reference 38). All PILs were saturated with $\mathrm{Ar}, \mathrm{H}_{2}$, or $\mathrm{O}_{2}$ prior to carrying out voltammetric measurements by bubbling the gas through the PILs for 10 minutes, and a blanket of the appropriate of gas was maintained above the PILs during the measurements.

Voltammetry In Vacuo. Voltammetry was performed in vacuo using an ultra-high vacuum (UHV) chamber with a base pressure of $2 \times 10^{-8}$ mbar. An in-line mass spectrometer (Vacuum Generator SX200, 1-200 amu quadrupole mass spectrometer, operated with an ESS European Spectrometry Systems power supply and software) was positioned directly above the electrochemical cell. The electrochemical cell contained a $\mathrm{Pd} / \mathrm{H}$ reference electrode and $\mathrm{Pt}$ wire working and counter electrodes that were connected to an external potentiostat. $\mathrm{The} \mathrm{Pd} / \mathrm{H}$ reference electrodes gave a stable potential over the course of the experiments (52 days). A piece of tubing, with a valve that could be externally operated, was placed over one of the electrodes to collect gases emanating from the electrode. Calibration experiments were undertaken with the valve either open, or closed then opened, in order to determine from which electrode $\mathrm{H}_{2}$ was evolved (see Figure S1 in the Supporting Information for a schematic of the experimental setup).

\section{Results and Discussion}

Electrochemistry of PILs and Electroreduction of Excess Acids in PILs. Figure 1 shows cyclic voltammograms (CVs) recorded in three PILs synthesised using different methods. In each case, the CVs were recorded using a $25-\mu \mathrm{m}$ diameter Pt UME, and the PIL was saturated with $\mathrm{Ar}$ to remove any $\mathrm{O}_{2}$ from the liquids. In Figure $1 \mathrm{~B}$ and $1 \mathrm{~F}$, waves due to $\mathrm{Pt}$ oxide formation can be seen at potentials, $E,>1.0 \mathrm{~V}$ and $0.6 \mathrm{~V}$ (these waves cannot be clearly resolved 
in the other CVs due to the scale of the current). ${ }^{39}$ At the negative potential limit, a cathodic current flowed in each case, due to reduction of the PIL cations. ${ }^{14,31}$
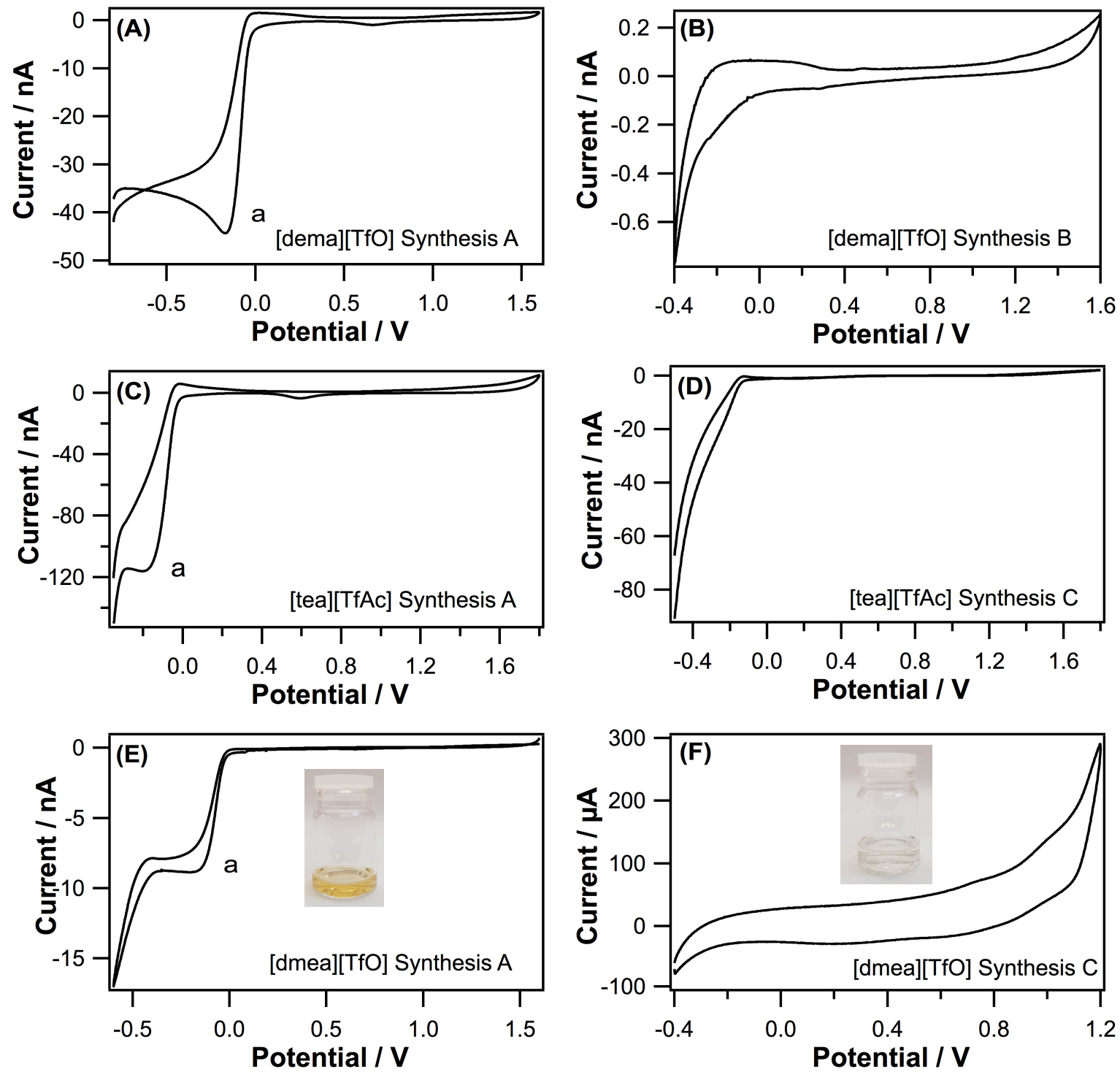

Figure 1. CVs of a series of Ar-saturated PILs recorded using a 25- $\mu \mathrm{m}$ diameter Pt UME. The applied potentials were cycled between (A) $-0.9 \mathrm{~V}$ (initial) and $1.6 \mathrm{~V}$ at $10 \mathrm{mV} \mathrm{s}{ }^{-1},(\mathrm{~B})-0.4 \mathrm{~V}$ (initial) and $1.6 \mathrm{~V}$ at $50 \mathrm{mV} \mathrm{s}^{-1},(\mathrm{C})-0.35 \mathrm{~V}$ (initial) and $1.8 \mathrm{~V}$ at $50 \mathrm{mV} \mathrm{s}^{-1}$, (D) $-0.45 \mathrm{~V}$ (initial) and $1.8 \mathrm{~V}$ at $50 \mathrm{mV} \mathrm{s}^{-1},(\mathrm{E})-0.6 \mathrm{~V}$ (initial) and $1.6 \mathrm{~V}$ at $50 \mathrm{mV} \mathrm{s}^{-1},(\mathrm{~F})-0.4 \mathrm{~V}$ (initial) and $1.2 \mathrm{~V}$ at $50 \mathrm{mV} \mathrm{s}^{-1}$. The insets in $\mathrm{E}$ and $\mathrm{F}$ show photographs of the PILs used to record the respective data. 
However, Figure 1A, 1C, and 1E clearly show a peak labelled "a", which does not appear in Figure $1 \mathrm{~B}, 1 \mathrm{D}$, or $1 \mathrm{~F}$, so there was some difference between liquids that were nominally the same, but which were synthesised using different methods. In general, we found that the use of Synthesis A (addition of neat acid to 5\% excess neat base) resulted in the appearance of peak a in the voltammograms. As well as yielding this additional peak in the CVs, it is notable that the PILs synthesised using different methods had different appearances. The insets of Figures 1E and $1 \mathrm{~F}$ show that samples of [dmea][TfO] synthesised using Syntheses A and C were brown and colorless, respectively. In all of our syntheses, we found that deep coloration of our PILs correlated with the presence of peak a during voltammetry. It is important to note that this work is not the first to show the anomalous reduction current in CVs of similar PILs at Pt electrodes at 0 V (note that some workers use Pt "reversible hydrogen electrodes" consisting of $\mathrm{H}_{2}$ gas flowing over Pt electrodes immersed in the PIL, but the potential of this reference electrode is within about $50 \mathrm{mV}$ of that of our $\mathrm{Pd} / \mathrm{H}$ electrode, so the results are comparable).$^{40-41}$ However, this peak has thus far not been conclusively attributed to a specific electrochemical process. Angell and co-workers did observe these peaks previously during voltammetry of PILs but the PILs had been saturated with $\mathrm{H}_{2} \cdot{ }^{31}$ They suggested that the peak resulted from reduction of the acid formed by $\mathrm{H}_{2}$ oxidation in $\mathrm{H}_{2}$-saturated PILs; when $\mathrm{H}_{2}$ is oxidised, the PIL anions are protonated to reform the parent acid (Equation 2), which is reduced at $E<0 \mathrm{~V}$ (Equation 3):

$\mathrm{H}_{2}+2 \mathrm{~A}^{-} \rightarrow 2 \mathrm{HA}+2 \mathrm{e}^{-}$

$$
2 \mathrm{HA}+2 \mathrm{e}^{-} \rightarrow \mathrm{H}_{2}+2 \mathrm{~A}^{-}
$$


where $\mathrm{A}^{-}$and HA represent the anion and parent acid of a generalised PIL, respectively. However, while this description is reasonable for voltammetry in $\mathrm{H}_{2}$-saturated media, it does not explain why cathodic waves are sometimes observed during voltammetry of $\mathrm{H}_{2}$-free PILs.

To identify the origin of the anomalous peak in our voltammograms, we first posited that electroreduction of undissociated acid remaining in some as-synthesised liquids may have been responsible. Our reasoning was based on Angell's observation of the peak in $\mathrm{H}_{2}$-saturated PILs; $;{ }^{31}$ given that the product of $\mathrm{H}_{2}$ oxidation (Equation 2) is the acid that is used to synthesise the PIL in the first place, it seems reasonable that excess acid in the PILs should also be reduced at this potential. To test whether reduction of excess acid in the PILs was responsible for the appearance of the peak in some of the voltammograms, those liquids that exhibited the peak during voltammetry were spiked with additional acid and reanalysed voltammetrically. Figures 2A-C show steady-state voltammograms of each PIL. Clearly, increasing the concentration of the parent acid in each PIL caused an increase in the cathodic current flowing negative of $E=0$ $\mathrm{V}$, indicating that the currents were due to reduction of excess acid in each PIL (note that the increase in cathodic current at $-0.4 \mathrm{~V}$ in Figure $2 \mathrm{C}$ is due to the reduction of the PIL cations, which occurred at a lower potential in [tea][TfEt] than in the [TfO $]^{-}$-based PILs. The concentration of acid in each PILs can be related to the steady-state current, $i_{\mathrm{ss}}$, flowing through the UME using Equation 4:

$i_{\mathrm{ss}}=4 n F a D C$ 

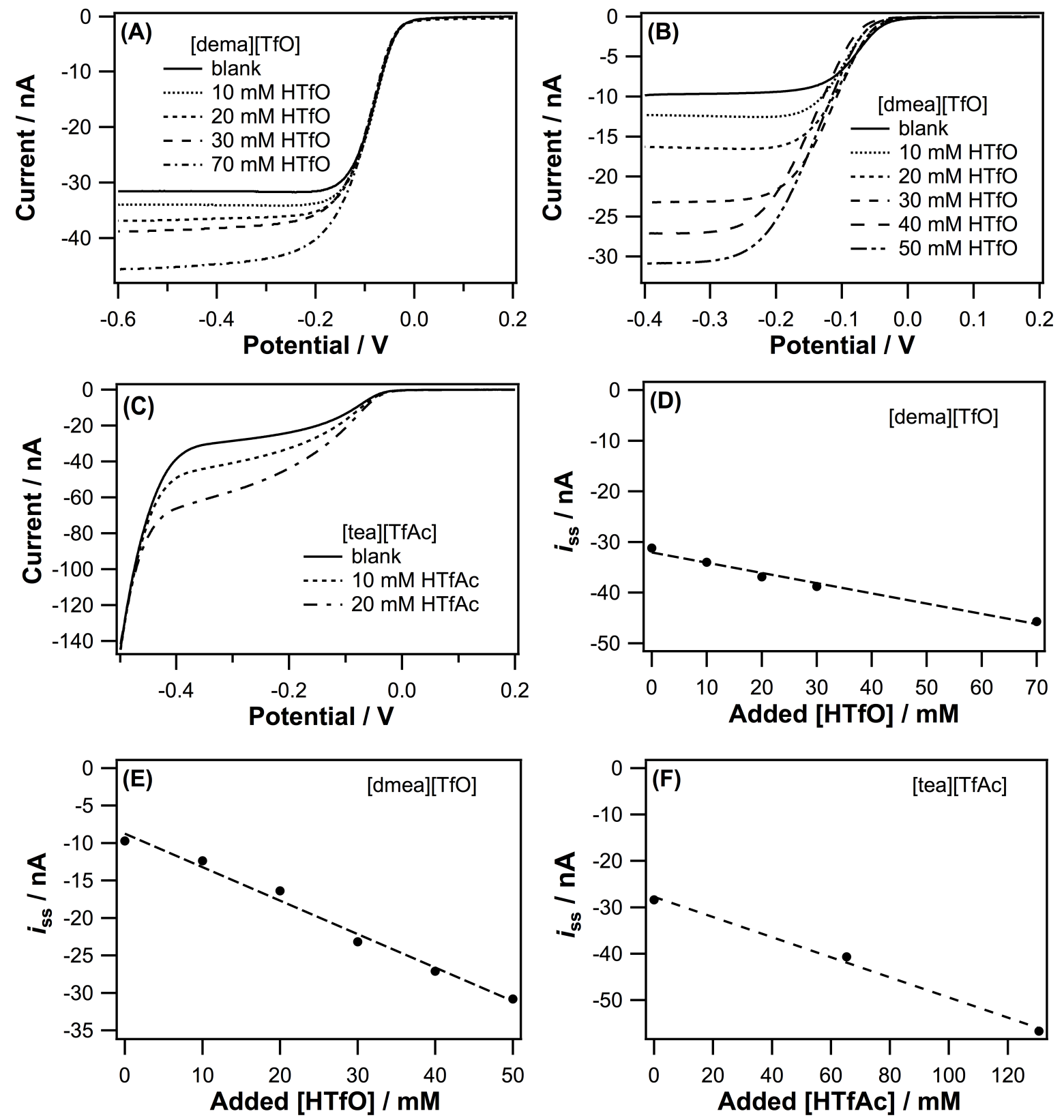

Figure 2. Steady-state voltammograms of Ar-saturated PILs containing increasing concentrations of parent acids. Applied potentials were swept from (A) $0.2 \mathrm{~V}$ to $-0.6 \mathrm{~V}$ at 10 $\mathrm{mV} \mathrm{s}^{-1}$, (B) $0.2 \mathrm{~V}$ to $-0.4 \mathrm{~V}$ at $10 \mathrm{mV} \mathrm{s}^{-1}$ and (C) $0.2 \mathrm{~V}$ to $-0.5 \mathrm{~V}$ at $5 \mathrm{mV} \mathrm{s}$. The voltammograms were recorded using a $12.5-\mu \mathrm{m}$ radius $\mathrm{Pt} \mathrm{UME}$ at (A and $\mathrm{C}$ ) room temperature and (B) $55^{\circ} \mathrm{C}$. Figures $\mathrm{D}-\mathrm{F}$ show plots of the steady-state cathodic current, $i_{\mathrm{ss}}, v s$. the concentration of added acid, with a dashed line of best fit. 
where $n$ is the stoichiometric number of electrons transferred, $F$ is the Faraday constant, $a$ is the radius of the UME, $D$ is the diffusion coefficient of the acid, and $C$ is its concentration. $i_{\mathrm{ss}}$ was measured at each concentration of added acid and the resulting relationships are shown in Figures 2D-F. $i_{\mathrm{ss}}$ increased linearly as the concentration of added acid increased (in agreement with Equation 4), and non-zero intercepts are visible in each figure, due to the presence of acid in each as-synthesised PIL. Extrapolation of the lines of best fit in Figure 2D-F to $i_{\mathrm{ss}}=0.0 \mathrm{~A}$ gives initial concentrations of parent acid of $160 \mathrm{mM}$ in [dema][TfO], $20 \mathrm{mM}$ in [dmea][TfO], and $230 \mathrm{mM}$ in [tea][TfAc]. Consideration of Equation 4 demonstrates that $D$ can be determined from the slopes of the lines of best fit and the calculated values are $D_{\mathrm{TfOH}}=4.2 \times 10^{-7} \mathrm{~cm}^{2} \mathrm{~s}^{-1}$ in [dema][TfO], $D_{\mathrm{TfOH}}=9.2 \times 10^{-7} \mathrm{~cm}^{2} \mathrm{~s}^{-1}$ in [dmea][TfO], and $D_{\mathrm{TfAcH}}=5.2 \times 10^{-7} \mathrm{~cm}^{2} \mathrm{~s}^{-1}$ in [tea][TfAc]. These values can be compared with values between $0.226 \times 10^{-7} \mathrm{~cm}^{2} \mathrm{~s}^{-1}$ and $3.13 \times$ $10^{-7} \mathrm{~cm}^{2} \mathrm{~s}^{-1}$ determined during a study of mass transport of hydrogen bis(trifluoromethanesulfonyl)imide (which is larger than the acids used here) in series of aprotic ionic liquids. $^{42}$

Chronoamperometric experiments were undertaken to further test the accuracy of the measured $C$ and $D$ values of the various parent acids in the as-synthesised PILs. Figure 3A-3C shows chronoamperograms of as-synthesised [dema][TfO], [dmea][TfO], and [tea][TfAc] (those used to record the voltammograms in Figures 2A, 2B, and 2C). In each case, the applied potential was stepped from a value where reduction of the excess acid did not occur, to one where the reduction of acid occurred at the diffusion-controlled rate. The decay in current, $i$, after a potential step at a UME can be described by the Shoup-Szabo expression: ${ }^{43-44}$

$i=4 n F a D C f(t)$ 
where $f(t)$ is given by:

$$
f(t)=0.7854+0.8862 \tau^{-\frac{1}{2}}+0.2154 \exp \left(-0.7823 \tau^{-\frac{1}{2}}\right)
$$
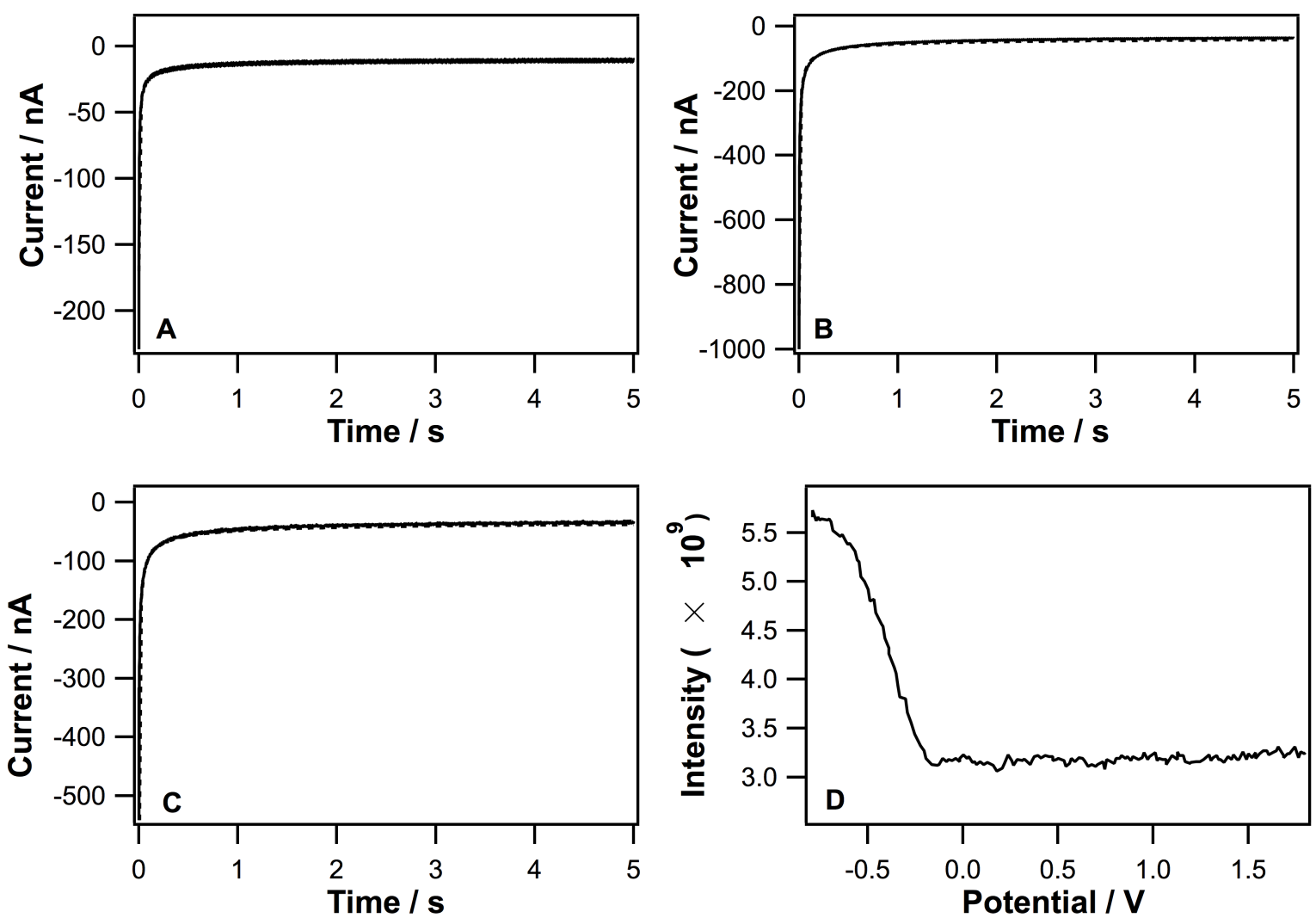

Figure 3. (A-C) Chronoamperograms of Ar-saturated PILs recorded using a $12.5-\mu \mathrm{m}$ radius $\mathrm{Pt}$ disk UME in [dema][TfO], [dmea][TfO], and [tea][TfAc] (solid lines). In A, the applied potential was stepped from $0.6 \mathrm{~V}$ to $-0.5 \mathrm{~V}$ in [dema][TfO] at $25{ }^{\circ} \mathrm{C}$. In $\mathrm{B}$, the applied potential was stepped from $0.2 \mathrm{~V}$ to $-0.4 \mathrm{~V}$ in [dmea][TfO] at $55^{\circ} \mathrm{C}$. In $\mathrm{C}$, the applied potential was stepped from $0.2 \mathrm{~V}$ to $-0.3 \mathrm{~V}$ in [tea][TfAc] at $25{ }^{\circ} \mathrm{C}$. The dashed lines show the best-fits of the experimental data to Equation 5. (D) Mass spectrometry traces (at $m / z=2$ ) recorded when a Pt electrode immersed in [dema][TfO] was swept from $1.8 \mathrm{~V}$ to $-0.8 \mathrm{~V}$ at $50 \mathrm{mV} \mathrm{s}^{-1}$. 
and $\tau$ is given by:

$$
\tau=\frac{4 D t}{a^{2}}
$$

Theoretical curves were generated using Equation 5 and the values of $C$ and $D$ determined previously using voltammetry of each PIL. These fits are shown in Figure 3A-C (dashed lines) and the agreement between the experimental and theoretical curves is excellent, giving us confidence in our estimates of the $C$ and $D$ (above) for the parent acids in the as-synthesised PILs.

A further experiment was then undertaken, in order to confirm that the anomalous waves in the CVs in Figures 1A, 1C, and 1E were due to the reaction shown in Equation 3. A sample of [dema][TfO], to which $0.1 \mathrm{M} \mathrm{TfOH}$ was added, was inserted into a glass vial, along with electrodes connected to a potentiostat. The assembled cell was then inserted into a vacuum chamber connected to a mass spectrometer. Due to the very low vapor pressure of ionic liquids, it is possible to study ionic liquids under high vacuum conditions. ${ }^{45}$ Figure $3 \mathrm{D}$ shows an increase in the $m / z=2$ signal at $E<0 \mathrm{~V}$ when $E$ was swept from $1.8 \mathrm{~V}$ to $-0.8 \mathrm{~V}$, confirming that $\mathrm{H}_{2}$ was produced at $E<0 \mathrm{~V}$ (our calibration experiments confirmed that the gas was evolved from the Pt working electrode). Therefore, we can conclude that not only is excess acid present in some of the PILs, but simple voltammetry can allow its quantification. 

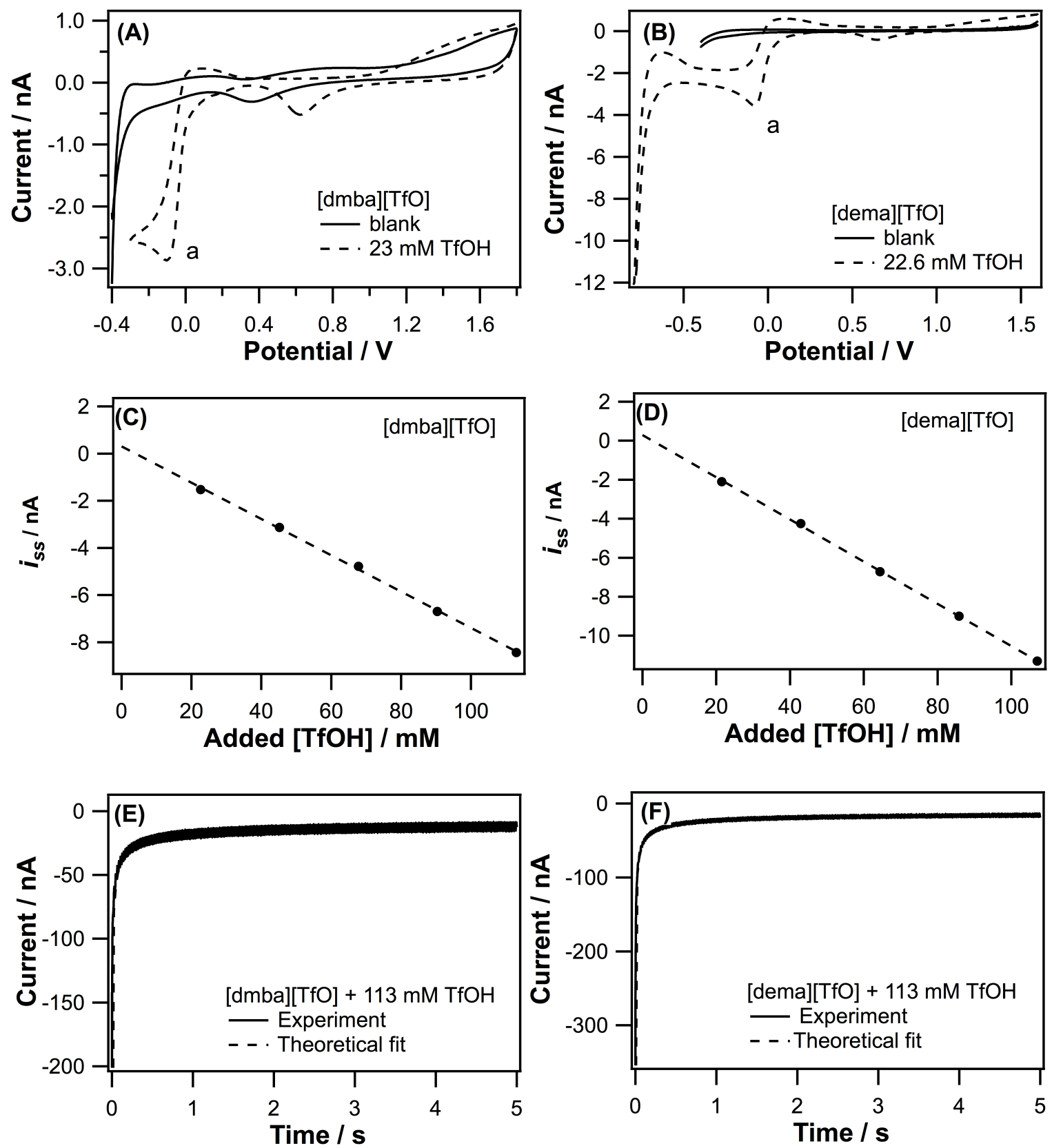

Figure 4. (A) CVs of [dmba][TfO] recorded using a Pt UME at $50 \mathrm{mV} \mathrm{s}^{-1}$ in the presence and absence of added TfOH. (B) CVs of [dema][TfO] recorded using a Pt UME at $50 \mathrm{mV} \mathrm{s}^{-1}$ in the presence and absence of added TfOH. (C) Graph of the steady-state current for $\mathrm{H}_{2}$ evolution in [dmba][TfO] during voltammetry at $5 \mathrm{mV} \mathrm{s}^{-1} v s$. the concentration of added TfOH. (D) Graph of the steady-state current for $\mathrm{H}_{2}$ evolution in [dema][TfO] during voltammetry at $5 \mathrm{mV} \mathrm{s}^{-1} v s$. the concentration of added TfOH. (E) Chronoamperogram of [dmba][TfO] recorded at $-0.3 \mathrm{~V}$ after addition of $113 \mathrm{mM} \mathrm{TfOH}$ to the PIL (solid line). The dashed line shows the best fit of the experimental data to Equation 5. (F) Chronoamperogram of [dema][TfO] recorded at $-0.4 \mathrm{~V}$ 
after addition of $113 \mathrm{mM}$ TfOH to the PIL (solid line). The dashed line shows the best fit of the experimental data to Equation 5.

It is notable that not all of the PILs synthesised during our study showed the anomalous voltammetric wave a. We found that $[\mathrm{dmba}][\mathrm{TfO}]$ could be synthesised using any of the methods and did not show any excess acid-reduction wave. Acid-free [dema][TfO], on the other hand, could only be reliably made using Synthesis C, and the solid lines in Figure 4A and 4B show CVs of samples of [dmba][TfO] and [dema][TfO] synthesised using Method A and C, respectively. No reduction wave is apparent near $0 \mathrm{~V}$, but after addition of $23 \mathrm{mM} \mathrm{TfOH}$, reduction waves with onset potentials near $0 \mathrm{~V}$ appeared (labelled ' $\mathrm{a}$ ' on each figure). The concentration of acid in these PILs was gradually increased, and the resulting steady-state cathodic currents are shown in Figure 4C and D as a function of the concentration of added acid. From the slope of the best-fit lines in Figure $4 \mathrm{C}$ and $\mathrm{D}, D_{\mathrm{TfOH}}$ in $[\mathrm{dmba}][\mathrm{TfO}]$ is $1.59 \times 10^{-7} \mathrm{~cm}^{2}$ $\mathrm{s}^{-1}$, and $D_{\mathrm{TfOH}}$ in [dema][TfO] is $2.28 \times 10^{-7} \mathrm{~cm}^{2} \mathrm{~s}^{-1}$, in reasonable agreement with that determined previously for the as-synthesised PIL containing excess acid. Chronoamperometry was also used to study these liquids and Figure 4E and 4F show the chronoamperograms recorded in each PIL containing $113 \mathrm{mM}$ added $\mathrm{TfOH}$. The dashed line in each figure shows the theoretical curve generated using Equation 5 and values of $C_{\mathrm{TfOH}}=113 \mathrm{mM}$ (the concentration of acid added), $D_{\mathrm{TfOH}}$ in $[\mathrm{dmba}][\mathrm{TfO}]=1.59 \times 10^{-7} \mathrm{~cm}^{2} \mathrm{~s}^{-1}$, and $D_{\mathrm{TfOH}}$ in $[$ dema $][\mathrm{TfO}]=2.28 \times$ $10^{-7} \mathrm{~cm}^{2} \mathrm{~s}^{-1}$. Clearly, the theoretical curves fit the experimental curves extremely well, giving us confidence in our estimates of $C$ and $D$ and demonstrating that any excess acid in the assynthesised PILs was at concentrations below the limit of detection of our method. 
In cases where measurable concentrations of acids persisted in PILs, which was generally when Synthesis A was used, loss of volatile base during the reaction must have occurred due to the exothermicity of the reaction, despite that fact that all of our reaction mixtures were kept cold (in ice baths) during very slow dropwise addition of the acids. We also tried to use dry ice/acetone baths to keep our reaction mixtures cold (as done previously ${ }^{21}$ ). During Synthesis A (5\% excess base), there was insufficient base present to mitigate loss of the volatile base during the reaction, so excess acid generally resulted. Synthesis B, on the other hand, sometimes resulted in the presence of excess acid. The lower propensity of this method to result in excess acid in the as-prepared liquids is attributed to the higher initial concentration of bases in the reaction mixtures, which mitigated loss or decomposition of some of the volatile base from the reaction mixture. By contrast, we found that Synthesis C (addition of $1.0 \mathrm{M} \mathrm{TfOH}$ (aq) to 5\% molar excess of neat base, with subsequent removal of base and water under vacuum) reliably produced stoichiometric PILs. The synthesis of PILs using aqueous acid/base mixtures has previously been reported as resulting in PILs that contain unavoidably high water contents. ${ }^{16}$ This was not, however, our experience, with all PILs synthesised using Synthesis C containing less than 200 ppm water after drying. Therefore, based on our observations, we recommend the use of Synthesis C to those researchers attempting to synthesise highly-ionic PILs.

\section{Detection of Unreacted Base in the PILs and the Prospects for Vacuum Purification of}

PILs. While the bases used to form our PILs are electrochemically inactive within the electrochemical window of the PILs, we show here that it is possible to indirectly detect the bases within PILs using voltammetry. Oxidation of $\mathrm{H}_{2}$ in PILs yields protons that can then either be accepted by anions of a PIL (Equation 2) or by any neutral base (Equation 8) present.

$\mathrm{H}_{2}+2 \mathrm{~B} \rightarrow 2 \mathrm{HB}^{+}+2 \mathrm{e}^{-}$ 

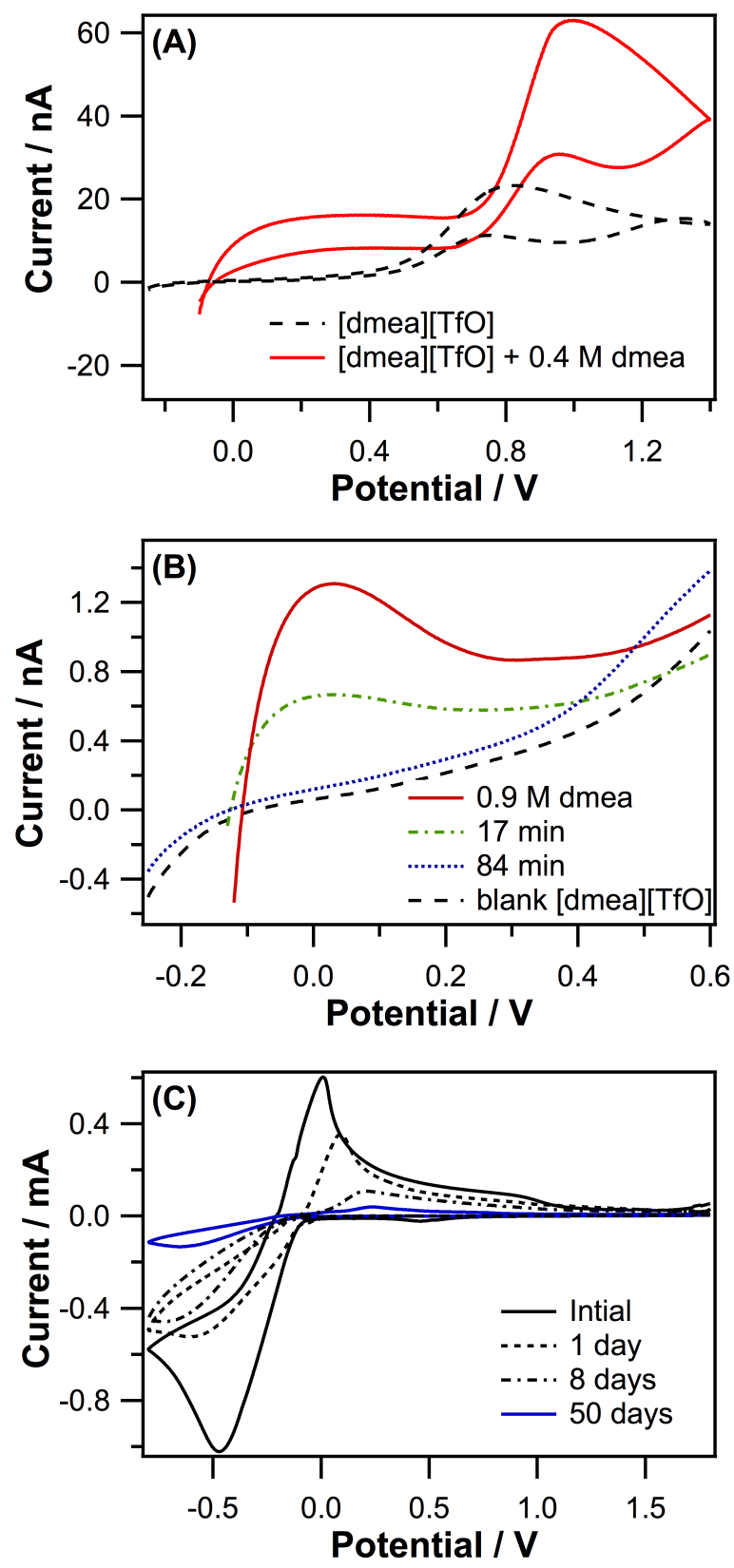

Figure 5. (A) Pt UME CVs of $\mathrm{H}_{2}$-saturated [dmea][TfO] at $50 \mathrm{mV} \mathrm{s}^{-1}$ (dashed line). A Pt wire counter electrode and $\mathrm{Pd} / \mathrm{H}$ reference electrode completed the cell. The red line shows the $\mathrm{CV}$ recorded after addition of $0.4 \mathrm{M}$ dmea. (B) UME voltammograms (swept positive at $5 \mathrm{mV} \mathrm{s}^{-1}$ ) of $\mathrm{H}_{2}$-saturated [dmea][TfO] using the same electrodes as in part A. $0.9 \mathrm{M}$ dmea was added to the PIL and the red CV (solid line) was recorded. The green (dot-dashed) and blue (dotted) responses were recorded 17 and $84 \mathrm{~min}$, respectively after addition of the base. The blank response is shown by the black dashed line. All experiments with [dmea][TfO] were conducted at $65{ }^{\circ} \mathrm{C}$. (C) $\mathrm{CVs}$ recorded using a Pt-wire electrode at $50 \mathrm{mV} \mathrm{s}^{-1}$. The initial $\mathrm{CV}$ was recorded 
at atmospheric pressure, then at $2.6 \times 10^{-7} \mathrm{mbar}$ (dashed), and $9.5 \times 10^{-8} \mathrm{mbar}$ (dot-dashed). The blue $\mathrm{CV}$ was recorded after bringing the chamber to ambient pressure using $\mathrm{N}_{2}$.

Protonation of the base should occur at less positive potentials than protonation of the anions of the PILs, as the anions are weak conjugate bases. Figure 5A shows $\mathrm{CVs}$ of $\mathrm{H}_{2}$-saturated [dmea][TfO], before and after addition of the parent base dmea to the PIL. Oxidation of $\mathrm{H}_{2}$, with subsequent protonation of the PIL anions, is visible as the anodic peak positive of $0.4 \mathrm{~V}$ in Figure 5A (dashed black line). After addition of $0.4 \mathrm{M}$ dmea, a new oxidation process with an onset near $0 \mathrm{~V}$ appeared (red solid line), corresponding to the reaction shown in Equation 8. This anodic process was only observed when the PILs were saturated with $\mathrm{H}_{2}$ (see Figure S2A in the SI). Oxidation of $\mathrm{H}_{2}$ and protonation of anions was still visible as a second oxidation wave positive of $0.5 \mathrm{~V}$. Therefore, the neutral base in the PIL can be monitored by measuring the anodic currents at potentials below about $0.4 \mathrm{~V}$. Figure $5 \mathrm{~B}$ shows a voltammogram recorded in the same PIL in the absence (dashed black line) and presence (red line) of dmea at $5 \mathrm{mV} \mathrm{s}^{-1}$ and within a smaller electrochemical window for clarity. The green (dot-dashed) and blue (dotted) lines show subsequent CVs recorded $17 \mathrm{~min}$ and $84 \mathrm{~min}$, respectively, after addition of the base. The anodic $\mathrm{H}_{2}$-oxidation currents decreased in magnitude as time progressed, showing that dmea (boiling point $36.5^{\circ} \mathrm{C}$, and vapor pressure above pure liquid of $495 \mathrm{~mm} \mathrm{Hg}$ ) rapidly evaporated from the PIL, and that its loss could be monitored electrochemically. Similar patterns were observed when using [dema][TfO] and [dmba][TfO]. In both of these liquids, new anodic peaks were observed in voltammograms around $0 \mathrm{~V}$ after the addition of the respective bases, and these peaks decreased in size as time progressed (Figures S2B and S2C in the Supporting Information). On the other hand, when excess base was added to [tea][TfAc], no significant difference in the 
$\mathrm{H}_{2}$-oxidation voltammograms was observed (Figure 1D in the Supporting Information). The most likely explanation for this behaviour is that [tea][TfAc] always contains some tea due to the lower driving force for proton transfer from $\mathrm{TfAcH}$ to tea, so addition of base had a negligible effect on $\mathrm{H}_{2}$ oxidation in the PIL.

Figure 5C (solid black line) shows a CV of [dema][TfO] containing $0.1 \mathrm{M} \mathrm{TfOH}$. This voltammogram was recorded in-situ in a high vacuum chamber under atmospheric pressure and shows a peak for reduction of $\mathrm{TfOH}$ (with an onset potential near $0 \mathrm{~V}$ ) in the negative-going sweep, and a subsequent $\mathrm{H}_{2}$-oxidation peak in the positive sweep (as expected for this PIL). The pressure in the vacuum chamber was then lowered to $10^{-7} \mathrm{mbar}$, and voltammograms were recorded over the course of several days. As time progressed, the TfOH-reduction peak and $\mathrm{H}_{2}$ oxidation peak decreased in size but, even after 50 days, some acid reduction was visible negative of $0 \mathrm{~V}$ during voltammetry of the PIL (blue CV). Given that $\mathrm{TfOH}$ could not be removed entirely from [dema][TfO] after almost 2 months at $10^{-7}$ mbar, the removal of excess TfOH using a simple rotary pump setup will clearly not be possible within reasonable timeframes. Therefore, contrary to what has been suggested in the literature, ${ }^{28}$ not all neutral species can be removed from PILs using vacuum purification. While excess amines can be removed from our PILs relatively readily, excess acid in PILs are very persistent, most likely a result of the strong hydrogen-bonding ability of the acids.

Usefulness and Limitations of Walden Plots and NMR Spectroscopy for Studying the Ionicity of PILs. So far, we have demonstrated the usefulness of electrochemical methods to study excess parent acids and bases in PILs. To demonstrate the usefulness and limitations of Walden plots for determining the presence of acids in PILs (and so compare this approach with our electrochemical method), samples of $[$ dema $][\mathrm{TfO}]$ and $[\mathrm{dmba}][\mathrm{TfO}]$ were synthesised using Method C, and their conductivity and viscosity are shown as part of the Walden plot in Figure 6. 
"Poor" analogues of each PIL were then synthesised by deliberately spiking the PILs first with $0.25 \mathrm{M}$ of the parent acid, then with $0.50 \mathrm{M}$ of the acid, and finally with de-ionised water. The conductivity and viscosity of these PILs are also included in Figure 6. The data recorded for the as-synthesised [dema][TfO] and [dmba][TfO] are within about $10 \%$ of the theoretical line (measured vertically), in agreement with data reported previously for similar PILs, and meaning that the ionicity of these PILs is below that of the fully dissociated electrolyte. ${ }^{17}$ Addition of the parent acid (TfOH) to each PIL has a negligible effect on the position of the PIL on the Walden plot (data points 1-3 and 6-8 respectively), demonstrating that the presence of significant concentrations of the parent acid affected neither the conductivity nor the viscosity of the PILs. However, adding water to PILs shifts their positions on the Walden plot towards the top-right corner, following the gradient of the ideal line. This change in position on the plot demonstrates that adding water to the PILs decreases their viscosities, and thereby increasing their conductivity, but without changing the mechanism of ion conduction (a change in slope from the diagonal, ideal line can indicate the occurrence of Grotthus hopping mechanism).$^{14}$ Therefore, it is clear that the use of Walden-plot analysis of as-synthesised PILs would not in itself provide any insights into presence of excess acids.

Figure 7 shows ${ }^{1} \mathrm{H}$ NMR spectra of [tea][TfAc] and [dmba][TfO] before and after addition of acid and water. The top spectrum of Figure $7 \mathrm{~A}$ is that of the as-synthesised [tea][TfAc] and shows a resonance at $9 \mathrm{ppm}<\delta<10 \mathrm{ppm}$, which is attributable to the exchangeable proton bound to the nitrogen of the ammonium cation (full spectra are shown in Figures S3-S12 of the Supporting Information). ${ }^{20}$ As increasing concentrations of TfAcH were added to the PIL, a broad, low-intensity peak appeared between 12 and $13 \mathrm{ppm}$. This peak is 


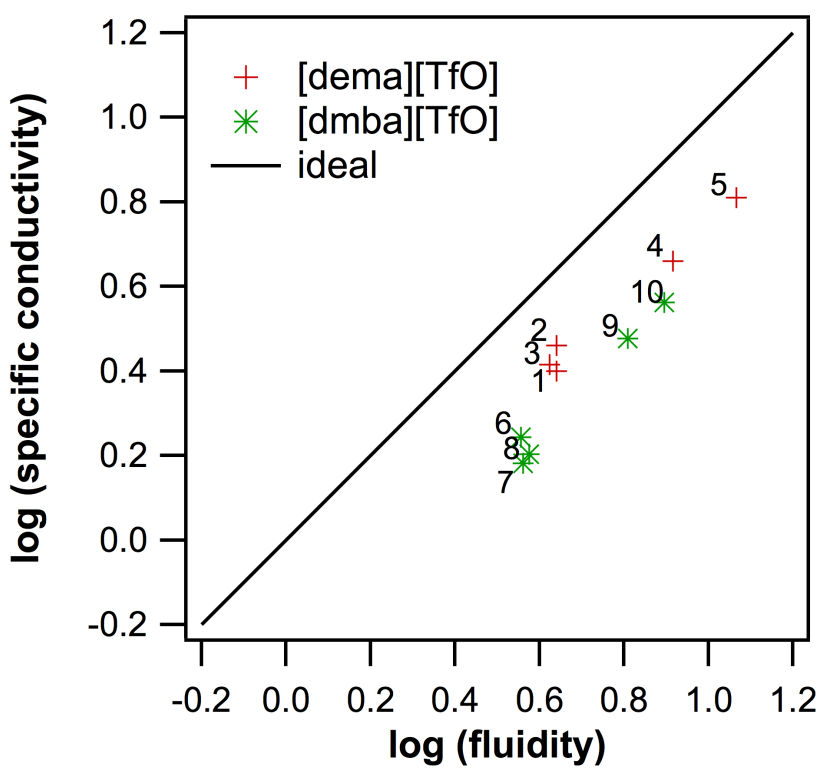

Figure 6. Walden Plot of log of the molar conductivity versus log of the fluidity of [dema][TfO] and [dmba][TfO]. Each PIL was synthesised according to synthetic method $\mathrm{C}$ in the Experimental Section and conductivity and viscosity data were recorded at $40{ }^{\circ} \mathrm{C}$. The concentrations of added TfOH and $\mathrm{H}_{2} \mathrm{O}$ in the PILs were (1) $0 \mathrm{M} \mathrm{TfOH}, 0.013 \mathrm{M} \mathrm{H}_{2} \mathrm{O}$. 2) 0.25 $\mathrm{M} \mathrm{TfOH}, 1.054 \mathrm{M} \mathrm{H}_{2} \mathrm{O}$. 3) $0.50 \mathrm{M} \mathrm{TfOH}, 1.053 \mathrm{M} \mathrm{H}_{2} \mathrm{O}$. 4) $0.50 \mathrm{M} \mathrm{TfOH}, 5.063 \mathrm{M} \mathrm{H}_{2} \mathrm{O}$. 5) 0.50 $\mathrm{M}$ TfOH, 7.876 $\mathrm{M} \mathrm{H}_{2} \mathrm{O}$. 6) 0 M TfOH, 0.093 $\mathrm{M} \mathrm{H}_{2} \mathrm{O}$. 7) $0.25 \mathrm{M} \mathrm{TfOH}, 0.165 \mathrm{M} \mathrm{H}_{2} \mathrm{O}$. 8) $0.50 \mathrm{M}$ TfOH, 0.702 $\mathrm{M} \mathrm{H}_{2} \mathrm{O}$. 9) $0.50 \mathrm{M}$ TfOH, 3.502 $\mathrm{M} \mathrm{H}_{2} \mathrm{O}$. 10) $0.50 \mathrm{M} \mathrm{TfOH}, 4.593 \mathrm{M} \mathrm{H}_{2} \mathrm{O}$.
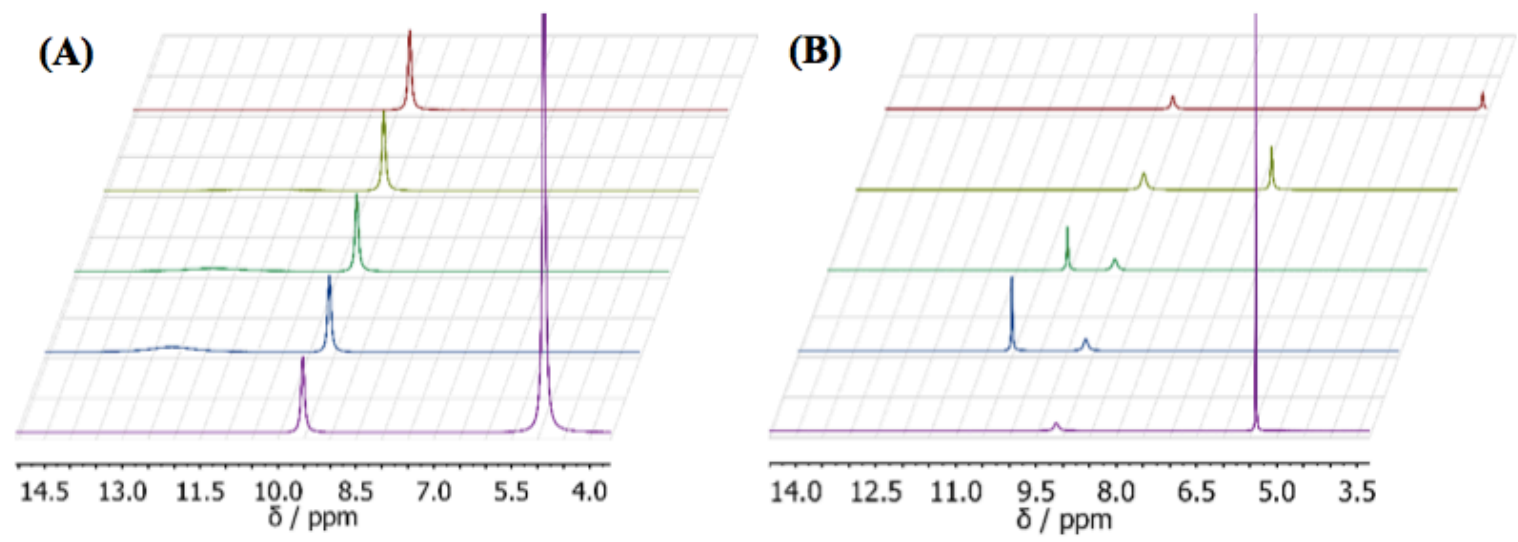

Figure 7. (A) ${ }^{1} \mathrm{H}$ NMR spectra of (from top to bottom) as-synthesised [tea][TfAc], and [tea][TfAc] containing 1.4 M TfAcH, 2.2 M TfAcH, 3.1 M TfAcH, and 3.1 M TfAcH/15 M H $\mathrm{H}_{2} \mathrm{O}$. (B) ${ }^{1} \mathrm{NMR}$ spectra of (from top to bottom) as-synthesised [dmba][TfO], and [dmba][TfO] containing 1.6 M TfOH, 4.0 M TfOH, 5.5 M TfOH, and 5.5 M TfOH/15 M H $\mathrm{H}_{2} \mathrm{O}$. 
associated with the exchangeable proton associated with $\mathrm{TfAcH}$, and the broadness of the peak is likely due to this proton exchanging between the acid and the base. Even at $3.1 \mathrm{M}$ added TfAcH, the peak between 12 and 13 ppm was very broad and low in intensity, and lower concentrations of excess acid could not be reliably detected using ${ }^{1} \mathrm{H}$ NMR spectrocopy. The usefulness of ${ }^{1} \mathrm{H}$ NMR spectroscopy in studying excess acid in this PIL is complicated further by the presence of water. The bottom spectrum of Figure 7A is that of [tea][TfAc] containing 3.1 M TfAcH and 15 $\mathrm{M} \mathrm{H}_{2} \mathrm{O}$. Comparison with the spectrum of the PIL containing 3.1 M TfAcH and no added water reveals that the peak between 12 and 13 ppm disappeared upon addition of $\mathrm{H}_{2} \mathrm{O}$, and a large peak, appeared at $\delta \sim 5 \mathrm{ppm}$. In the presence of $\mathrm{H}_{2} \mathrm{O}$, the proton resonates between the acid and the $\mathrm{H}_{2} \mathrm{O}$ on a faster timescale than the NMR timescale, resulting in the single peak. Therefore, it is not possible to differentiate between excess acid in the PIL and water in the PIL. Given that water is an extremely common contaminant impurity in PILs (and RTILs in general), this is especially problematic.

Figure 7B shows ${ }^{1} \mathrm{H}$ NMR spectra of as-prepared [dmba][TfO], and [dmba][TfO] containing various amounts of added $\mathrm{TfOH}$ and $\mathrm{H}_{2} \mathrm{O}$. As was the case for the [tea][TfAc] spectra, a single resonance due to the exchangeable proton of the $[\mathrm{dema}]^{+}$cation is observed at 9 $\mathrm{ppm}<\delta<10 \mathrm{ppm}$. In the spectrum of the as-prepared [dmba][TfO], an additional peak is observed at $\delta=3.4 \mathrm{ppm}$ and associated with trace water in the sample. However, when $\mathrm{TfOH}$ was added to the [dmba][TfO], the peak at $3.4 \mathrm{ppm}$ disappeared and new peaks appeared, which increased in $\delta$ (up to about $10.5 \mathrm{ppm}$ ) as the concentration of acid increased. These peaks can be attributed to protons exchanging between $\mathrm{TfOH}$ and the $\mathrm{H}_{2} \mathrm{O}$ in the samples. As more $\mathrm{TfOH}$ was added, the protons sat predominantly on the acid, shifting the peak to higher $\delta$. However, when water was deliberately added to the sample (bottom spectrum of Figure 7B), the peak shifted to a lower $\delta$, as the protons sat predominantly on the water. 
In summary, it is clear that excess acids can be identified in each PIL using ${ }^{1} \mathrm{H}$ NMR spectroscopy, but the usefulness of ${ }^{1} \mathrm{H}$ NMR spectroscopy for quantitatively studying such species is complicated by the presence of the protic impurity $\mathrm{H}_{2} \mathrm{O}$, a phenomenon that has been recognised previously. ${ }^{21}$ This limitation is a particular disadvantage, given that water is one of the most common contaminants in PILs (and RTILs in general). ${ }^{32}$

Effects of Unreacted Acid in PILs. Given that we have demonstrated that some syntheses of PILs can results in the presence of excess acid, and that the acid is very stable and detectable using voltammetry, an important question is whether excess acids in PILs have a significant effect on the properties of PILs. A simple visual demonstration of the effects of excess acids in PILs is shown in Figure 8. $8 \mathrm{mM}$ ferrocene was added to each of the PILs used in our study and, in those PILs containing excess acid, ferrocene was oxidised, as shown by the change in the color of the solution from yellow to blue (most clearly evident in the [TfO]-based liquid and confirmed by cyclic voltammetry).

We studied whether excess acid could have an effect of the electrochemical properties of PILs by studying the oxygen reduction reaction (ORR; $\mathrm{O}_{2}+4 \mathrm{e}^{-}+4 \mathrm{H}^{+} \rightarrow 2 \mathrm{H}_{2} \mathrm{O}$ ) in the PILs. The ORR is the cathode reaction in low-temperature fuel cells and has been studied in a range of RTILs and PILs, both due to its fundamental importance as an example of an electrocatalytic reaction, and as some researchers propose the development of PIL-based intermediatetemperature fuel cells. ${ }^{6,41,46-47}$ Figure 9 shows linear sweep ORR voltammograms recorded in $\mathrm{O}_{2}$ saturated neat, acid-free [dema][TfO] (blue) and acidified [dema][TfO] (red). Note that potentials in this figure are reported $v s$. that of the ferrocene/ferrocinium redox couple (visible at $0 \mathrm{~V})$ to avoid complications from changes in the acidity of the solution on the potential of the 


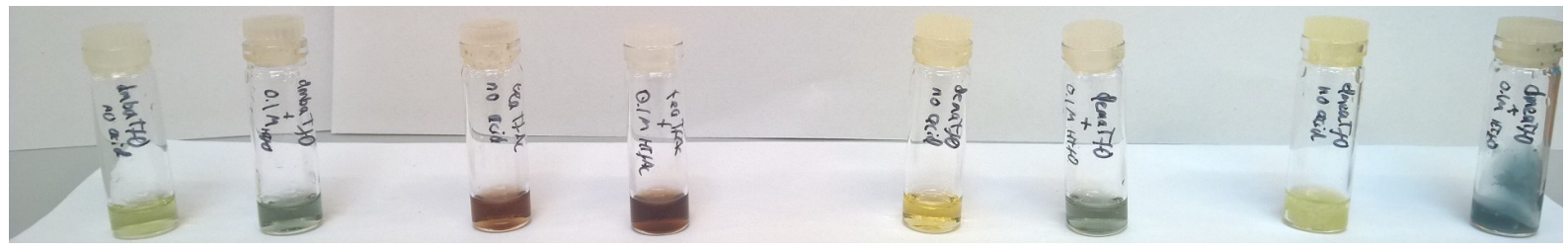

Figure 8. (From left to right) [dmba][TfO], [dmba][TfO] + 0.1 M TfOH, [tea][TfAc], [tea][TfAc] $+0.1 \mathrm{M}$ TfAcH, [dema][TfO], [dema][TfO] + 0.1 M TfOH, [dmea][TfO], [dmea][TfO] + 0.1 M $\mathrm{TfOH}$. All solutions contained $8 \mathrm{mM}$ ferrocene.

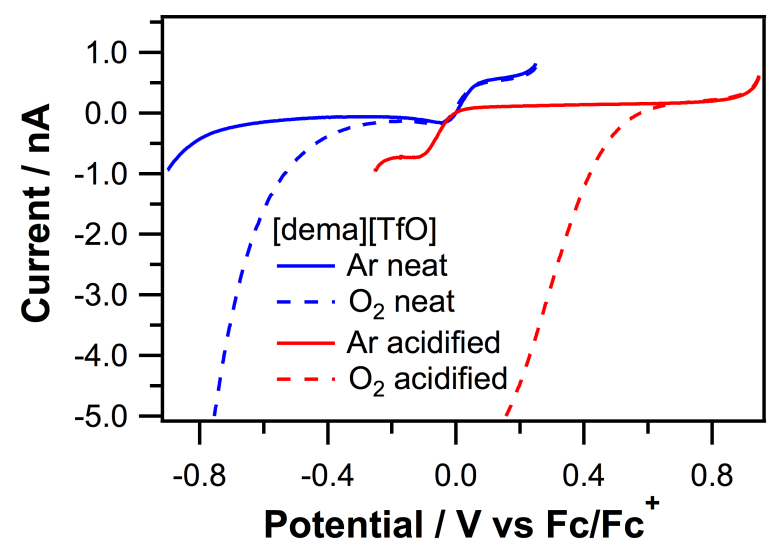

Figure 9. Linear sweep voltammograms recorded in [dema][TfO] at a 25- $\mu$ m diameter Pt UME. Potentials were swept negative at $5 \mathrm{mV} \mathrm{s}^{-1}$. Dashed lines show the responses obtained using $\mathrm{O}_{2}$ saturated PILs and solid lines show those recorded using Ar-saturated PILs. The blue lines show the responses recorded in the absence of excess $\mathrm{TfOH}$ and the red lines show those recorded in [dema][TfO] containing $107 \mathrm{mM}$ TfOH.

$\mathrm{Pd} / \mathrm{H}$ reference electrode (for reference, the ORR onset potential in the PIL is about $1.0 \mathrm{~V}$ positive of that of the $\mathrm{H}_{2}$-oxidation reaction in the $\mathrm{PIL}^{47}$ ). When the proton donor changed from the $[\text { dema }]^{+}$cation (in the neat liquid) to $\mathrm{TfOH}$ (in the acidified liquid), the ORR onset potential shifted positive by about $0.8 \mathrm{~V}$, from about $-0.2 \mathrm{~V}$ to about $0.6 \mathrm{~V}$. Friesen and co-workers have previously shown that the ORR onset potential in an aprotic RTIL (2,3-dimethylimidazolium trifluoromethanesulfonate) shifts positive by about $0.9 \mathrm{~V}$ when changing the $\mathrm{p} K_{\mathrm{a}}$ of proton donors 
from 10 (that of $[\mathrm{dema}]^{+}$) to -14 (that of $\left.\mathrm{TfOH}\right){ }^{48}$ Therefore, our data are in good agreement with that observed previously when using aprotic RTILs, and illustrate the importance of quantifying, and understanding the effects of, excess acids in PILs before using these media as solvents for electrochemical measurements.

\section{Conclusions}

We have demonstrated the usefulness of a simple ultramicroelectrode-voltammetry method for comparing the properties of PILs synthesised using several methods. The exothermic addition of neat acid to neat base can result in the loss or decomposition of the basic component of the PILs and electrochemical analysis reveals that the acid TfOH can be extremely stable in non-stoichiometric PILs, even under high vacuum. In contrast, excess amines readily evaporate from [TfO]-based PILs. The use of dry ice/acetone baths to keep reaction mixtures cold does not always prevent the loss of volatile bases from reaction mixtures. Therefore, based on our observations, we recommend the synthesis of [TfO $]^{-}$-based PILs using a solution-based approach, in which at least one component of the reaction mixture is dissolved in water. The excess water can then be readily removed under vacuum. We have also shown that the presence of unreacted acid dramatically alters the properties of PILs, including causing a $0.8 \mathrm{~V}$ shift in the onset potential for electrocatalytic oxygen reduction in the PIL [dema][TfO]. Thus, it is vital that those researchers interested in electrocatalysis in PILs (where onset potentials are often used as a measure of electrocatalytic performance) consider the presence of excess acids and bases in their liquids, and we hope that the methods described here will be of aid when studying such phenomena. 


\section{Supporting Information}

The Supporting Information is available free of charge on the ACS Publications website.

A schematic of the apparatus used for mass spectrometric analysis of evolved gas; hydrogen-oxidation voltammograms of PILs after addition of excess amines; NMR spectra of PILs.

\section{Acknowledgements}

We thank the Engineering and Physical Sciences Research Council for funding through Project EP/P002382/1 and the Centre for Doctoral Training in Fuel Cells and their Fuels (Project $\mathrm{EP} / \mathrm{L} 015749 / 1)$

\section{References}

1. Wilkes, J. S., A Short History of Ionic Liquids - from Molten Salts to Neoteric Solvents. Green Chem. 2002, 4, 73-80.

2. Hardacre, C.; Parvulescu, V., Catalysis in Ionic Liquids: From Catalyst Synthesis to Application. Royal Society of Chemistry: Cambridge, 2014.

3. Wasserscheid, P.; Welton, T., Ionic Liquids in Synthesis. Wiley-VCH Verlag \& Co.: Weinheim, 2008; Vol. 2.

4. Abbott, A. P.; McKenzie, K. J., Application of Ionic Liquids to the Electrodeposition of Metals. Phys. Chem. Chem. Phys. 2006, 8, 4265-4279.

5. Wei, D.; Ivaska, A., Applications of Ionic Liquids in Electrochemical Sensors. Anal. Chim. Acta 2008, 607, 126-135. 
6. Lee, S.-Y.; Ogawa, A.; Kanno, M.; Nakamoto, H.; Yasuda, T.; Watanabe, M., Nonhumidified Intermediate Temperature Fuel Cells Using Protic Ionic Liquids. J. Am. Chem. Soc. 2010, 132, 9764-9773.

7. Lewandowski, A.; Swiderska-Mocek, A., Ionic Liquids as Electrolytes for Li-Ion Batteries-an Overview of Electrochemical Studies. J. Power Sources 2009, 194, 601-609.

8. Ueno, K.; Tokuda, H.; Watanabe, M., Ionicity in Ionic Liquids: Correlation with Ionic Structure and Physicochemical Properties. Phys. Chem. Chem. Phys. 2010, 12, 1649-1658.

9. Nuthakki, B.; Greaves, T. L.; Krodkiewska, I.; Weerawardena, A.; Burgar, M. I.; Mulder, R. J.; Drummond, C. J., Protic Ionic Liquids and Ionicity. Aust. J. Chem. 2007, 60, 2128.

10. Sun, X.; Liu, S.; Khan, A.; Zhao, C.; Yan, C.; Mu, T., Ionicity of Acetate-Based Protic Ionic Liquids: Evidence for Both Liquid and Gaseous Phases. New J. Chem. 2014, 38, 3449-3456.

11. Greaves, T. L.; Drummond, C. J., Protic Ionic Liquids: Evolving Structure-Property Relationships and Expanding Applications. Chem. Rev. 2015, 115, 11379-11448.

12. Greaves, T. L.; Drummond, C. J., Protic Ionic Liquids: Properties and Applications. Chem. Rev. 2008, 108, 206-237.

13. Angell, C. A.; Byrne, N.; Belieres, J. P., Parallel Developments in Aprotic and Protic Ionic Liquids: Physical Chemistry and Applications. Acc. Chem. Res. 2007, 40, 1228-1236.

14. Yoshizawa, M.; Xu, W.; Angell, C. A., Ionic Liquids by Proton Transfer: Vapor Pressure, Conductivity, and the Relevance of $\Delta \mathrm{p} K_{\mathrm{a}}$ from Aqueous Solutions. J. Am. Chem. Soc. 2003, $125,15411-15419$. 
15. Belieres, J.-P.; Angell, C. A., Protic Ionic Liquids: Preparation, Characterization, and Proton Free Energy Level Representation. J. Phys. Chem. B 2007, 111, 4926-4937.

16. Burrell, G. L.; Burgar, I. M.; Separovic, F.; Dunlop, N. F., Preparation of Protic Ionic Liquids with Minimal Water Content and ${ }^{15} \mathrm{~N}$ NMR Study of Proton Transfer. Phys. Chem. Chem. Phys. 2010, 12, 1571-1577.

17. MacFarlane, D. R.; Forsyth, M.; Izgorodina, E. I.; Abbott, A. P.; Annat, G.; Fraser, K., On the Concept of Ionicity in Ionic Liquids. Phys. Chem. Chem. Phys. 2009, 11, 4962-4967.

18. Zhu, X.; Wang, Y.; Li, H., Do All the Protic Ionic Liquids Exist as Molecular Aggregates in the Gas Phase? Phys. Chem. Chem. Phys. 2011, 13, 17445-17448.

19. Leal, J. P.; Esperança, J. M. S. S.; Minas da Piedade, M. E.; Canongia Lopes, J. N.; Rebelo, L. P. N.; Seddon, K. R., The Nature of Ionic Liquids in the Gas Phase. J. Phys. Chem. A 2007, 111, 6176-6182.

20. Davidowski, S. K.; Thompson, F.; Huang, W.; Hasani, M.; Amin, S. A.; Angell, C. A.; Yarger, J. L., NMR Characterization of Ionicity and Transport Properties for a Series of Diethylmethylamine Based Protic Ionic Liquids. J. Phys. Chem. B 2016, 120, 4279-4285.

21. Hasani, M.; Yarger, J. L.; Angell, C. A., On the Use of a Protic Ionic Liquid with a Novel Cation to Study Anion Basicity. Chem. Eur. J. 2016, 22, 13312-13319.

22. Stoimenovski, J.; Izgorodina, E. I.; MacFarlane, D. R., Ionicity and Proton Transfer in Protic Ionic Liquids. Phys. Chem. Chem. Phys. 2010, 12, 10341-10347.

23. Miran, M. S.; Kinoshita, H.; Yasuda, T.; Susan, M. A. B. H.; Watanabe, M., Physicochemical Properties Determined by $\Delta \mathrm{p} K_{\mathrm{a}}$ for Protic Ionic Liquids Based on an Organic Super-Strong Base with Various Bronsted Acids. Phys. Chem. Chem. Phys. 2012, 14, 5178-5186. 
24. Tremblay, J.; Nguyen, N. L.; Rochefort, D., Hydrogen Absorption by a Palladium Electrode from a Protic Ionic Liquid at Temperatures Exceeding $100{ }^{\circ} \mathrm{C}$. Electrochem. Commun. 2013, 34, 102-104.

25. Mayrand-Provencher, L.; Rochefort, D., Origin and Effect of Impurities in Protic Ionic Liquids Based on 2-Methylpyridine and Trifluoroacetic Acid for Applications in Electrochemistry. Electrochim. Acta 2009, 54, 7422-7428.

26. Idris, A.; Vijayaraghavan, R.; Patti, A. F.; MacFarlane, D. R., Distillable Protic Ionic Liquids for Keratin Dissolution and Recovery. ACS Sust. Chem. Eng. 2014, 2, 1888-1894.

27. Johansson, K. M.; Izgorodina, E. I.; Forsyth, M.; MacFarlane, D. R.; Seddon, K. R., Protic Ionic Liquids Based on the Dimeric and Oligomeric Anions: Aco $\mathrm{H}_{\mathrm{X}-1}{ }^{-}$. Phys. Chem. Chem. Phys. 2008, 10, 2972-2978.

28. Nakamoto, H.; Watanabe, M., Bronsted Acid-Base Ionic Liquids for Fuel Cell Electrolytes. Chem. Commun. 2007, 2539-2541.

29. Anouti, M.; Caillon-Caravanier, M.; Dridi, Y.; Galiano, H.; Lemordant, D., Synthesis and Characterization of New Pyrrolidinium Based Protic Ionic Liquids. Good and Superionic Liquids. J. Phys. Chem. B 2008, 112, 13335-13343.

30. Miran, M. S.; Yasuda, T.; Susan, M. A. B. H.; Dokko, K.; Watanabe, M., Electrochemical Properties of Protic Ionic Liquids: Correlation between Open Circuit Potential for $\mathrm{H}_{2} / \mathrm{O}_{2}$ Cells under Non-Humidified Conditions and $\Delta \mathrm{p} K_{\mathrm{a}}$. RSC Adv. 2013, 3, 4141-4144.

31. Bautista-Martinez, J. A.; Tang, L.; Belieres, J. P.; Zeller, R.; Angell, C. A.; Friesen, C., Hydrogen Redox in Protic Ionic Liquids and a Direct Measurement of Proton Thermodynamics. J. Phys. Chem. C 2009, 113, 12586-12593. 
32. Wang, C.; Guo, L.; Li, H.; Wang, Y.; Weng, J.; Wu, L., Preparation of Simple Ammonium Ionic Liquids and Their Application in the Cracking of Dialkoxypropanes. Green Chem. 2006, 8, 603-607.

33. Blanchard, J. W.; Belières, J.-P.; Alam, T. M.; Yarger, J. L.; Holland, G. P., Nmr Determination of the Diffusion Mechanisms in Triethylamine-Based Protic Ionic Liquids. $J$. Phys. Chem. Lett. 2011, 2, 1077-1081.

34. Luo, H.; Baker, G. A.; Lee, J. S.; Pagni, R. M.; Dai, S., Ultrastable SuperbaseDerived Protic Ionic Liquids. J. Phys. Chem. B 2009, 113, 4181-4183.

35. Zhao, C.; Burrell, G.; Torriero, A. A. J.; Separovic, F.; Dunlop, N. F.; MacFarlane, D. R.; Bond, A. M., Electrochemistry of Room Temperature Protic Ionic Liquids. J. Phys. Chem. B 2008, 112, 6923-6936.

36. Liu, S.; Zhou, L.; Wang, P.; Zhang, F.; Yu, S.; Shao, Z.; Yi, B., Ionic-Liquid-Based Proton Conducting Membranes for Anhydrous $\mathrm{H}_{2} / \mathrm{Cl}_{2}$ Fuel-Cell Applications. ACS Appl. Mater. Interfaces 2014, 6, 3195-3200.

37. Díaz, M.; Ortiz, A.; Ortiz, I., Progress in the Use of Ionic Liquids as Electrolyte Membranes in Fuel Cells. J. Membr. Sci. 2014, 469, 379-396.

38. Zoski, C. G., Ultramicroelectrodes: Design, Fabrication, and Characterization. Electroanalysis 2002, 14, 1041-1051.

39. Ejigu, A.; Walsh, D. A., The Role of Adsorbed Ions During Electrocatalysis in Ionic Liquids. J. Phys. Chem. C 2014, 118, 7414-7422.

40. Mitsushima, S.; Shinohara, Y.; Matsuzawa, K.; Ota, K.-i., Mass Transportation in Diethylmethylammonium Trifluoromethanesulfonate for Fuel Cell Applications. Electrochim. Acta 2010, 55, 6639-6644. 
41. Johnson, L.; Ejigu, A.; Licence, P.; Walsh, D. A., Hydrogen Oxidation and Oxygen Reduction at Platinum in Protic Ionic Liquids. J. Phys. Chem. C 2012, 116, 18048-18056.

42. Bentley, C. L.; Bond, A. M.; Hollenkamp, A. F.; Mahon, P. J.; Zhang, J., Mass Transport Studies and Hydrogen Evolution at a Platinum Electrode Using Bis(Trifluoromethanesulfonyl)Imide as the Proton Source in Ionic Liquids and Conventional Solvents. J. Phys. Chem. C 2014, 118, 29663-29673.

43. Silvester, D. S.; Aldous, L.; Hardacre, C.; Compton, R. G., An Electrochemical Study of the Oxidation of Hydrogen at Platinum Electrodes in Several Room Temperature Ionic Liquids. J. Phys. Chem. B 2007, 111, 5000-5007.

44. Bard, A.; Faulkner, L., Electrochemical Methods: Fundamentals and Applications. $2^{\text {nd }}$ Edn. John Wiley \& Sons: p 864.

45. Alwast, D.; Schnaidt, J.; Law, Y. T.; Behm, R. J., A Novel Approach for Differential Electrochemical Mass Spectrometry Studies on the Decomposition of Ionic Liquids. Electrochim. Acta 2016, 197, 290-299.

46. Khan, A.; Lu, X.; Aldous, L.; Zhao, C., Oxygen Reduction Reaction in Room Temperature Protic Ionic Liquids. J. Phys. Chem. C 2013, 117, 18334-18342.

47. Walsh, D. A.; Ejigu, A.; Smith, J.; Licence, P., Kinetics and Mechanism of Oxygen Reduction in a Protic Ionic Liquid. Phys. Chem. Chem. Phys. 2013, 15, 7548-7554.

48. Switzer, E. E.; Zeller, R.; Chen, Q.; Sieradzki, K.; Buttry, D. A.; Friesen, C., Oxygen Reduction Reaction in Ionic Liquids: The Addition of Protic Species. J. Phys. Chem. C 2013, $117,8683-8690$. 